ISSN. 2775-4324 (Online)

Journal of Physical Activity and Sports

Volume 2, Nomor 2, Agustus 2021, 165-170

Journal of Physical Activity and Sports

\title{
Survey sarana dan prasarana pembelajaran softball di SMA Se- Kabupaten Jepara
}

\author{
Sirojul Habib ${ }^{1}$, Osa Maliki ${ }^{2}$, Donny Anhar Fahmi ${ }^{3}$ \\ Pendidikan Jasmani Kesehatan dan Rekreasi, Universitas PGRI Semarang \\ Jl. Dr. Cipto Semarang, Jawa Tengah, Indonesia \\ sirojulhabib8@gmail.com, osamaliki04@gmail.com,pgsdikipdonny@gmail.com
}

\begin{abstract}
Purpose of this study to determine how the facilities and infrastructure for softball learning in Senior High School Jepara Regency. This research uses qualitative research with a descriptive approach, with the subject of this research is the Senior High School teachers in Jepara district. The collecting data using interview, observation and documentation methods. The data analysis using methods that are carried out continuously with data reduction, data presentation and make a conclusions. The results showed that (1) From 9 State Senior High Schools in Jepara Regency had good softball facilities and infrastructure, because there were several schools that did not have the facilities. (2) The main inhibiting factor in the procurement of softball facilities is the price of equipment which is expensive and in large quantities. (3) Softball learning in the school has not run optimally, due to inadequate facilities and infrastructure. (4) The teacher is innovative enough in learning to modify the tools and how to play. The conclusion is that the price of softball equipment is very expensive and the amount of equipment is not small, so the implementation of softball learning in the schools has not been carried out properly, because of the lack of softball equipment and also requires a large field. It is hoped that schools whose facilities and infrastructure for softball learning are still inadequate should be available to immediately organize softball facilities and infrastructure while still considering the level of need, so the quality of learning outcomes for sports and health, softball material can run well and can also lift branches Softball in Jepara Regency has become a popular sport not only among students but also among the local community.
\end{abstract}

Keywords: Facilities and infrastructure, Physical Education, Softball.

\begin{abstract}
Abstrak
Tujuan dari penelitian ini adalah untuk mengetahui bagaimana sarana dan prasarana pembelajaran softball di SMA Kabupaten Jepara. Penelitian ini menggunakan penelitian kualitatif dengan pendekatan deskriptif, dengan subjek penelitian ini yaitu guru olahraga SMA se-kabupaten Jepara. Pengumpulan data menggunakan metode wawancara, observasi dan dokumentasi. Analisis data menggunakan metode yang dilakukan secara terus menerus dengan reduksi data, penyajian data dan penarikan kesimpulan. Hasil penelitian menunjukkan bahwa (1) Dari 9 SMA Negeri di Kabupaten Jepara memiliki sarana dan prasarana softball cukup baik, karena ada beberapa sekolah yang tidak mempunyai sarana. (2) Faktor penghambat utama dalam pengadaan sarana softball adalah harga peralatan yang mahal dan jumlahnya banyak. (3) Pembelajaran softball di sekolah belum berjalan secara maksimal, karena sarana dan prasarana yang kurang memadai. (4) Guru sudah cukup inovatif dalam pembelajaran untuk memodifikasi dari mulai alat dan cara bermain. Kesimpulanya adalah harga peralatan softball yang sangat mahal dan jumlah peralatan yang tidak sedikit, maka pelaksanaan pembelajaran softball di sekolah belum terlaksana dengan baik, karena kurangnya peralatan softball dan juga butuh lapangan yang luas. Diharapkan kepada pihak sekolah yang kondisi sarana dan prasarana pembelajaran softball masih kurang memadai hendaknya untuk ada untuk segera mengadakan sarana dan prasarana softball dengan tetap mempertimbangkan tingkat kebutuhan, sehingga kualitas hasil pembelajaran Pendidikan Jasmani Olahraga dan Kesehatan materi softball dapat berjalan dengan baik dan juga dapat mengangkat cabang softball di Kabupaten Jepara menjadi olahraga yang populer bukan hanya dikalangan siswa tapi juga dikalangan masyarakat setempat.
\end{abstract}

Kata kunci : Sarana dan prasarana, PJOK, Softball 


\section{PENDAHULUAN}

Dalam pembelajaran PJOK sarana prasarana merupakan salah satu faktor utama penunjang terlaksananya kegiatan belajar mengajar. Kelengkapan sarana prasaran PJOK seperti peralatan sepak bola, bola voli, bola basket, softball harus sebanding dengan dengan jumlah siswa yang ada, sehingga proses kegiatan belajar mengajar dapat berjalan dengan lancar dan tujuan pembelajaran dapat tercapai dengan baik. Bukan hanya sarana prasarana saja, namun peran tenaga pendidik juga sangat penting untuk meningkatkan kualitas mutu pendidikan di Indonesia melalui mata pelajaran PJOK. Menurut (Agustina, 2014:11) kondisi sebagian besar sekolah di Indonesia tidak memiliki sarana dan prasarana yang cukup layak untuk cabang olahraga yang berkaitan dengan materi pendidikan jasmani dan kesehatan.

Media atau alat dalam pendidikan di dunia olahraga dapat dikatakan sebagai sarana dan prasarana. Menurut Agus. S. Suryobroto (2004: 4), sarana atau alat adalah segala sesuatu yang diperlukan dalam pembelajaran pendidikan jasmani olahraga dan kesehatan, mudah dipindah bahkan dibawa oleh pelakunya atau siswa. Menurut Soepartono (2000: 5), secara umum prasarana berarti segala sesuatu yang merupakan penunjang terselenggaranya suatu proses (usaha atau pembangunan). Proses transfer ilmu tersebut dipengaruhi oleh sarana dan prasarana, sehingga tercapainya tujuan suatu ilmu pengetahuan yang dipengaruhi oleh suatu proses memiliki hubungan dengan sarana dan prasarana yang ada. Kebutuhan sarana dan prasarana pendidikan jasmani dalam pembelajaran pendidikan jasmani adalah sangat vital artinya bahwa pembelajaran pendidikan jasmani harus menggunakan sarana dan prasarana yang sesuai dengan kebutuhan dan cara mengontrol ataupun cara pakainya. Sehingga sarana dan prasarana tersebut haruslah ada dalam setiap pembelajaran pendidikan jasmani. Sarana dan prasarana juga harus memenuhi syarat agar tercipta proses pembelajaran pendidikan jasmani secara efektif.

Permasalahan muncul selama proses pembelajaran PJOK adalah prasarana lapangan lapangan yang tidak standar, yaitu lahan di depan sekolah yang di pakai untuk tempat upacara. Kurangnya sarana dan prasarana dapat mengakibatkan pembelajaran menjadi tidak maksimal, menghambat gerak siswa, siswa menjadi pasif untuk menunggu menggunakan sarana tersebut. Siswa akan mudah jenuh dan bosan Karena kurangnya sarana dan prasarana tersebut. Ini dapat mengakibatkan kebugaran dan pengetahuan siswa tidak tercapai dengan baik. Oleh karena itu sarana dan prasarana mata pelajaran PJOK di sekolah yang tersedia dangan jumlah siswa dan terkondisikan dengan baik agar proses pembelajaran dapat berjalan dengan baik dan optimal. Kurangnya sarana dan prasarana pembelajaran PJOK akan membuat proses pembelajaran menjadi kurang lancar dan tujuan pembelajaran tidak sepenuhnya tercapai karena kurangnya sarana pendidikan jasmani dapat menghambat memanipulasi gerak pada siswa. Siswa akan mengantri dalam pergantian menggunakan peralatan pendidikan jasmani, siswa akan menjadi bosan dan siswa banyak beristirahat. maka sarana pendidikan jasmani harus disesuaikan dengan jumlah siswa 
dan mengkondisikannya dengan baik agar pembelajaran pendidikan jasmani dapat berjalan dengan lancar dan mendukung.

Softball merupakan permainan beregu yang mengutamakan memukul dan melempar. Berdasarkan KI dan KD dalam mata pelajaran PJOK disebutkan akan lebih baik diberikan pembelajaran softball. Namun hal tersebut belum dilaksanakan dengan baik disetiap jenjang sekolah, karena terdapat beberapa hal yang dapat menghambatnya yaitu cabang olahraga softball masih asing bagi beberapa sekolah terutama para siswa dan sarana prasarana yang kurang lengkap karena minimnya lapangan untuk bermain permainan softball dan peralatan softball yang mahal dan jumlahnya yang sangat banyak. Softball sendiri merupakan cabang olahraga yang kurang populer pada kalangan siswa, khususnya siswa di SMA Negeri se-Kabupaten Jepara, karena cabang olahraga softball adalah cabang olahraga yang cukup sulit karena seorang atlet softball harus menguasai beberapa aspek yaitu kecepatan (speed), kelincahan (agility), dan ketepatan (accuracy).

Berdasarkan obervasi dan wawancara yang telah dilakukan di SMA Negeri 1 Tahunan pada tanggal 10 Agustus 2020, menurut Bapak Arizal Muzakki, S.P.d "permasalahan terjadi pada saat pembelajaran PJOK materi softball di sekolah belum berjalan sebagaimana mestinya, karena peralatan softball kurang menunjang untuk pemberian materi dan juga lapangan di sekolah kurang memadai untuk pembelajaran materi softball”. Sedangkan di SMA Negeri 1 Welahan pada saat pelaksanaan Magang 3 peralatan yang ada untuk pembelajaran softball hanya ada 2 bat (pemukul), namun untuk bolanya menggunakan bola kasti. Maka dari itu penulis ingin mengetahui bagaimana sarana dan prasarana pembelajaran PJOK materi softball dalam permainan bola kecil di SMA se-kabupaten Jepara

\section{METODE PENELITIAN}

Dalam penelitian ini menggukan pendekatan kualitatif deskriptif, Menurut Suharsimi Arikunto (2014:3) merupakan penelitian yang benar-benar hanya memaparkan apa yang terdapat atau terjadi dalam sebuah kancah, lapangan atau wilayah tertentu. Data yang terkumpul diklasifikasikan atau dikelompok-kelompokkan menurut jenis, sifat atau kondisinya. Sesudah datanya lengkap kemudian dibuat kesimpulan. Menurut Sugiyono (2018:4) penelitian kualitatif berarti proses eksplorasi dan memaknai perilaku individu dan kelompok, menggambarkan masalah sosial atau masalah kemanusiaan.

Adapun subjek dalam penelitian ini adalah Guru-guru mata pelajaran PJOK di SMA Negeri kabupaten. Fokus penelitian lebih diarahkan bagaimana kondisi dan kelayakan sarana dan prasarana pembelajaran softball dalam materi permainan bola kecil pada mata pelajaran PJOK di SMA sekabupaten Jepara. Data yang dikumpulkan dalam penelitian ini meliputi data primer dan data sekunder. Sumber data primer diperoleh dari hasil wawancara langsung dengan guru olahraga SMA se-kabupaten Jepara tahun pelajaran 2020. Sedangkan sumber data sekunder diperoleh dari berbagai sumber kepustakaan yang relevan dengan penelitian dan internet, diantaranya 38 Undang-undang Sarana dan 
Prasarana pembelajaran Pendidikan Jasmani Olahraga dan Kesehatan, artikel tentang sarana dan prasarana pembelajaran Pendidikan Jasmani Olahraga dan Kesehatan, serta buku-buku tentang teori sarana dan prasarana pembelajaran Pendidikan Jasmani Olahraga dan Kesehatan.

Teknik pengumpulan data ini dengan melakukan wawancara dengan Guru-guru mata pelajaran PJOK dengan mendasarkan bagaimana sarana dan prasarana cabang olahraga softball dalam materi permainan bola kecil pada mata pelajaran PJOK di SMA se-kabupaten Jepara. Penelitian ini menggunakan pengujian validitas isi (content validity) yang artinya membandingkan antara isi instrumen dengan isi atau rancangan yang telah ditetapkan. Dalam hal ini kondisi saana dan prasarana pembelajaran pendidikan jasmani olahraga dan kesehatan dalam materi softball ditinjau dari jumlah sarana dan prasarana yang dimiiki. Langkah-langkah pengumpulan data dalam penelitian ini sebagai berikut :

a. Mendata jumlah sekolah menengah atas di kabupaten Jepara.

b. Mendata sarana dan prasarana cabang olahraga softball di masing-masing sekolah.

c. Mendeskripsikan jumlah dan kondisi sarana dan prasarana cabang olahraga softball di sekolah masing-masing.

\section{HASIL DAN PEMBAHASAN}

Hasil penelitian tentang survei sarana dan prasarana pembelajaran softball dalam materi permainan bola keci pada mata pelajaran PJOK di SMA se-Kabupaten Jepara Tahun Ajaran 2020 dilakukan di 9 SMA Negeri se-Kabupaten Jepara. Data diperoleh melalui observasi dan wawancara secara langsung dengan Guru PJOK SMA Negeri se-Kabupaten Jepara, dengan cara mendatangi sekolah secara satu-persatu. Data yang dijadikan identifikasi meliputi data-data yang termasuk dalam sarana dan prasarana pembelajaran softball pada mata pelajaran softball mengenai jumlah dan keadaan sarana dan prasarana tersebut. Sarana dan prasarana softball sendiri meliputi bola softball, body protector, helm, pemukul (batt), base, dan sarung tangan (gloves).

Jika melihat hasil data ketersediaan sarana dan prasarana pembelajaran PJOK materi softball di SMA se-Kabupaten Jepara, maka dapat dikatakan jumlah sarana dan prasarana yang dimiliki saat ini cukup untuk digunakan dalam pembelajaran softball. berikut adalah rangkuman secara menyeluruhnya.

Tabel 1. Hasil penelitian sarana softball di SMA Kabupaten Jepara

\begin{tabular}{llcccccc}
\hline No & Sekolah & \multicolumn{9}{c}{ Jumlah Peralatan } \\
\cline { 3 - 7 } & $\begin{array}{c}\text { Bola } \\
\text { softball }\end{array}$ & $\begin{array}{c}\text { Body } \\
\text { protector }\end{array}$ & Helm & Pemukul & Base & Gloves \\
1. & SMA N 1 Jepara & 2 & 0 & 2 & 1 & 0 & 3 \\
2. & SMA N 1 Tahunan & 12 & 1 & 6 & 5 & 3 & 13 \\
\hline 3. & SMA N 1 Welahan & 5 & 0 & 0 & 10 & 0 & 3 \\
\hline 4. & SMA N 1 Mayong & 6 & 0 & 0 & 1 & 0 & 10 \\
\hline 5. & SMA N 1 Nalumsari & 0 & 0 & 0 & 0 & 0 & 0 \\
6. & SMA N 1 Mlonggo & 0 & 0 & 0 & 0 & 0 & 0 \\
\hline
\end{tabular}




\begin{tabular}{lllllllc}
\hline 7. & SMA N 1 Bangsri & 5 & 1 & 6 & 6 & 4 & 10 \\
8. & SMA N 1 Kembang & 3 & 5 & 0 & 1 & 0 & 10 \\
9. & SMA N 1 Donorojo & 3 & 1 & 3 & 2 & 0 & 4 \\
\hline
\end{tabular}

Berdasarkan data diatas, sarana dan prasarana pembelajaran softball di SMA se-Kabupaten Jepara masih dalam kategori kurang untuk pembelajaran, karena banyak sekolah yang tidak mempunyai peralatan softball dan lapangan yang memadai untuk pembelajaran softball dengan baik. Kenyataan ini diambil berdasarkan observasi dan wawancara dengan Guru mata pelajaran PJOK di SMA Kabupaten Jepara. Faktor penghambat dari kurangnya atau bahkan tidak mempunyai peralatan softball keseluruhan di sekolah adalah karena harga peralatan softball yang mahal dan jumlah peralatan softball yang tidak sedikit, dan juga para Guru beranggapan bahwa cabang olahraga softball belum begitu populer dan masih sedikit minat untuk bermain softball.

Dari 9 sekolah SMA Negeri di Kabupaten Jepara hanya ada 2 sekolah yang memiliki peralatan dan lapangan yang memadai untuk pembelajaran softball yaitu SMA Negeri 1 Bangsri dan SMA Negeri 1 Tahunan. Dan ada 2 sekolah yang sama sekali tidak mempunyai sarana yang memadai untuk pembelajaran PJOK materi softball di sekolah yaitu SMA Negeri 1 Mlonggo dan SMA Negeri 1 Nalumsari. Di SMA Negeri 1 Mlonggo mempunyai prasarana yang sangat memadai untuk pembelajaran softball, karena memiliki lapangan sepakbola yang terletak di sebelah sekolah, namun tidak memiliki sarana pembelajaran softball, kemudian di SMA Negeri 1 Nalumsari sarana dan prasarananya sama sekali tidak menunjang untuk pembelajaran softball. Untuk yang lainnya bisa dikategorikan cukup, karena rata-rata yang sekolah punya hanya sebatas pemukul (batt), gloves, bola dan helm. Untuk base mereka bisa memodifikasi dengan keset atau sejenisnya. Karena pembelajaran yang dilakukan di sekolah tidak sepenuhnya melakukan praktik permainan softball, jadi hanya sebatas perkenalan dan melakukan teknik dasar lempar, tangkap dan memukul dalam permainan softball.

Keterbatasan lapangan olahraga di SMA Negeri se-kabupaten Jepara dapan disiasati Guru PJOk dengan memakai lapangan sepakbola Kecamatan, seperti SMA Negeri 1 Kembang dan SMA Negeri 1 Donorojo yang letaknya tidak jauh dari sekolah. Cara ini cukup efektif untuk mengatasi keterbatasan lapangan olahraga di sekolah

\section{KESIMPULAN}

Kesimpulanya adalah harga peralatan softball yang sangat mahal dan jumlah peralatan yang tidak sedikit, maka pelaksanaan pembelajaran softball di sekolah belum terlaksana dengan baik, karena kurangnya peralatan softball dan juga butuh lapangan yang luas. Diharapkan kepada pihak sekolah yang kondisi sarana dan prasarana pembelajaran softball masih kurang memadai hendaknya untuk ada untuk segera mengadakan sarana dan prasarana softball dengan tetap mempertimbangkan tingkat kebutuhan, sehingga kualitas hasil pembelajaran Pendidikan Jasmani Olahraga dan Kesehatan materi softball dapat 
berjalan dengan baik dan juga dapat mengangkat cabang softball di Kabupaten Jepara menjadi olahraga yang populer bukan hanya dikalangan siswa tapi juga dikalangan masyarakat setempat.

\section{DAFTAR PUSTAKA}

Agus S. Suryobroto. (2004). Sarana dan Prasarana Pendidikan Jasmani: Universitas Negeri Yogyakarta:Fakultas Ilmu Keolahragaan.

Agustina, Nora. (2014). Survei Sarana dan Prasarana Pendidikan Jasmani Olaraga dan Kesehatan di Sekolah Luar Biasa Negeri Kendal dan Sekolah Luar Biasa ABC swadaya di Kabupaten Kendal. Jurnal Of Physical Education and Sport and Recreations.Vol 39(11) tahun 2014: hal 1396-1401.

Arikunto, Suharsimi. (2014). Prosedur Penelitian Suatu Pendekatan Praktik. Jakarta : Rineka Cipta.

Sugiyono. (2018). Metode Penelitian Kualitatif. Bandung: Alfabeta.

Soepartono. (2000). Sarana dan Prasarana Pembelajaran Pendidikan Jasmani Olahraga dan Kesehatan Cabang. Departemen Pendidikan dan Kebudayaan. 